\title{
Acute toxicity of cerium oxide, titanium oxide and iron oxide nanoparticles using standardized tests
}

Ana García ${ }^{\mathrm{a}}$, Roser Espinosa ${ }^{\mathrm{a}}$, Lucía Delgado ${ }^{\mathrm{a}}$, Eudald Casals ${ }^{\mathrm{b}}$, Edgar González $^{\mathrm{b}}$, Víctor Puntes $^{\mathrm{b}, \mathrm{c}}$, Carlos Barata $^{\mathrm{d}}$, Xavier Font $^{\mathrm{a}}$ and Antoni Sánchez ${ }^{\mathrm{a}, *}$

${ }^{a}$ Composting Research Group, Department of Chemical Engineering, Escola

d'Enginyeria, Universitat Autònoma de Barcelona, 08193 Bellaterra, Spain

b Institut Català de Nanotecnologia, Campus de la Universitat Autònoma de Barcelona, 08193 Bellaterra, Spain

c Insitut Català de Recerca i Estudis Avançats, Passeig Lluís Companys, 23, 08010

Barcelona, Spain

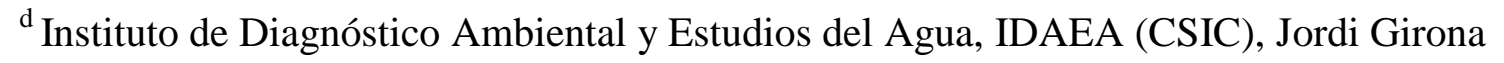
18-26, 08034 Barcelona, Spain

* Corresponding author: Antoni Sánchez

Phone: 34-935811019

Fax: 34-935812013

E-mail address: antoni.sanchez@uab.cat

Pre-print of: García, A. et al., "Acute toxicity of cerium oxide, titanium oxide and iron oxide nanoparticles using standardized tests" in Desalination (Ed. Elsevier), vol. 269, issues 1-3 (March 2011), p. 136-141. The final version is available at DOI 10.1016/j.desal.2010.052 


\section{Abstract}

In this study, several standard toxicity tests have been performed on selected inorganic nanoparticles. Acute toxicity tests were selected according to their extensive use in toxicological studies and included phytotoxicity using several seeds, Daphnia magna and a bioluminescent test (Microtox®). All of them have been used in several international regulations as toxicity assays. In the case of nanoparticles (NPs), we have studied those of cerium oxide, titanium dioxide and iron oxide. Iron oxide NPs are well known and broadly used and were selected because of their low toxicity. Titanium dioxide and cerium oxide NPs are currently being used in several fields such as photocatalysis and medical applications, but their toxicity effects have been scarcely studied. Our results revealed that cerium NPs are extremely toxic in the entire set of tests conducted (inhibition higher than $80 \%$ at very low concentrations for the bioluminescence test and LC50 $=0.012 \mathrm{mg} / \mathrm{ml}$ of mortality in the assays of Daphnia magna), whereas titanium NPs were practically inert in terms of toxicity (values similar to those of controls). The possible toxicological effect of the solvents necessary to stabilize NPs in liquid medium for the three cases (stabilizers) has been also studied. Only in the germination test (phytotoxicity) of some seeds they showed some detrimental effect to germination. In general, the standardized tests proposed in this study have proved to be very useful in the determination of NPs toxicity when no or few data are available, although further work is necessary in the case of the germination test.

Keywords: Inorganic Nanoparticles; Vibrio fischeri; Phytotoxicity; Acute Toxicity; Daphnia magna; Stabilizer. 


\section{Introduction}

As a result of advances in methods of producing nanoparticles (NPs) with controlled morphology and composition, as well as the incipient development of protocols for large-scale synthesis, in recent years the use of engineered inorganic nanoparticles has increased exponentially. These nanoparticles are the base for manufacturing new materials that project and materialize a variety of applications. Some of them have been inserted as raw matter in the productive sector to be a part of the dynamic supply of consumer products and support the research and development tasks. In this context it is necessary to assess the environmental and biological risk factors of exposure to man made nanoparticles either in the colloidal phase or incorporated in materials that may interact with atmospheric and biological media. Apart from the exposure through intended use, unwanted dispersion (spill) or (nano)waste management have also to be considered as critical pathway to insert nanoparticles in the environment. Another concern is the potential release of large amounts of nanoparticles to soils, water or as by products of their use in remediation strategies of removal of PCB and toxins [1-2]. It is significant that nearly one billion dollars have been allocated to the U.S. EPA in 2009 for remediation projects [3]; therefore the benefits of using some NPs for environmental remediation have to be balanced with their potential risks.

Nanoparticles are sensitive to the nature and evolution of the entities that conform the interaction environment. The response of the nanoparticle environment can be extremely complex and diverse, depending on a variety parameters involved, which makes difficult modeling their environmental fate. Once NPs leave from the laboratory they may be either aggregated into microscopic particles or embedded in the exposed materials, they may corrode and dissolve or they may provoke morphological 
modifications to the entities they interact with. The surface of the NPs surface constant modifications and it is indeed through its surface that the NPs interact with its environment. Thus, in biological environments, the toxic effects of nanoparticles will depend not only on the initial morphological properties, composition, size, additives and synthesis method employed, but also, on the physico-chemical evolution in the surroundings $[4,5,6]$. Therefore, it is necessary to evaluate risk factors considering the type of morphology, size, method of producing nanoparticles and the type of target and conditions of interaction [7-8].

In this work we examine the environmental impact of nanoparticles of metallic oxides, magnetite $\left(\mathrm{Fe}_{3} \mathrm{O}_{4}\right)$, titanium $\left(\mathrm{TiO}_{2}\right)$ and cerium $\left(\mathrm{CeO}_{2}\right)$, and the suitability of the standardized toxicity tests currently used to measure their impact. Due to its physicochemical properties, $\mathrm{CeO}_{2}$ can protect biological tissues from the oxidative stress caused by reactive oxygen species [9]. Accordingly, $\mathrm{CeO}_{2}$ is being used as an antioxidant to block the enzymatic activity that causes glaucoma [10] and other retinal disorders [11]. Ceria based catalytic filters have also been implemented in automobiles around the world to reduce diesel exhaust particles, while few cytotoxic and environmental studies of the impact of the use of these nanoparticles have been performed [12]. $\mathrm{Fe}_{3} \mathrm{O}_{4}$ opened an important scenario of applications in nanotherapy [13], removal of contaminants [14], data processing and storage [14], among others while it has been traditionally used in industry as pigment, catalyst or magnetic coating. Finally, $\mathrm{TiO}_{2}$ has raised a number of concerns and also deserves special attention. $\mathrm{TiO}_{2}$ is present in sunscreens due to its consideration as safe physical sunscreen agent, which reflects and scatters both UVB $(290-320 \mathrm{~nm})$ and UVA $(320-400 \mathrm{~nm})$, the principal cause of skin cancer. Also, $\mathrm{TiO}_{2}$ is used to mineralize many undesired organic pollutants [15]. On the other hand, as $\mathrm{TiO}_{2}$ absorbs substantial UV radiation, in aqueous 
media-despite the low penetration of UV in water-could yield to hydroxyl species and these species may cause substantial damage to DNA $[16,17,18]$.

In consequence, the main objectives of this paper are: i) to evaluate the suitability of some standard toxicity tests when applied to water or wastewater containing NPs and ii) to collect information about the toxicity of new NPs that are scarcely studied.

\section{Materials and methods}

\subsection{Nanoparticles preparation}

Three different kinds of metal oxide NPs were synthesized in aqueous phase, using milli-Q grade water. All reagents were purchased from Sigma-Aldrich (99\% purity grade) and used as received. All the synthesis procedures are based in preexisted ones available in the scientific literature with modifications to be adapted to large-scale yields. Briefly, for $\mathrm{CeO}_{2} \mathrm{NPs}$, based on Zhang et al [19], the $\mathrm{Ce}^{3+}$ ions from $\mathrm{Ce}\left(\mathrm{NO}_{3}\right)_{3}$ salt are oxidized at basic $\mathrm{pH}$ conditions to $\mathrm{Ce}^{4+}$ using hexamethylenetetramine (HMT). Then, $\mathrm{CeO}_{2}$ nanocrystals precipitate and are further stabilized in aqueous medium with the same reagent HMT, which form the double electrical layer to prevent agglomeration.

For $\mathrm{TiO}_{2} \mathrm{NPs}$, based on Pottier et al [20], the synthesis procedure consists on the decomposition of titanium tetrachloride $\left(\mathrm{TiCl}_{4}\right)$ at acidic $\mathrm{pH}$ (from 2 to 6). After that, it follows a growing step of the nanocrystals, carried out in an oven at $70^{\circ} \mathrm{C}$, purification by means of centrifugation and resuspension with tetramethylammonium hydroxide (TMAOH) to stabilize NPs. Depending on the $\mathrm{pH}$ during the growing step, the obtained 
size and shape of the $\mathrm{TiO}_{2}$ varies from small size and spherical-like (from $5 \mathrm{~nm}$, not used in this work) to bigger particles (around $10 \mathrm{~nm}, \mathrm{pH}=5$, used in this work).

For $\mathrm{Fe}_{3} \mathrm{O}_{4}$ NPs, based on Massart's method [21-22] amounts of 1 mmol iron (II) chloride $\left(\mathrm{FeCl}_{2}\right)$ and $2 \mathrm{mmol}$ iron (III) chloride $\left(\mathrm{FeCl}_{3}\right)$ were dissolved in $50 \mathrm{~mL}$ deoxygenated water and then added dropwise to $50 \mathrm{~mL}$ of a solution of $1 \mathrm{M}$ deoxygenated TMAOH. After 30 min of vigorous stirring under a $\mathrm{N}_{2}$ stream, the $\mathrm{Fe}_{3} \mathrm{O}_{4}$ precipitate was washed by soft magnetic decantation and redissolved in $1 \mathrm{mM}$ TMAOH to obtain the final stable colloidal solution of $\mathrm{Fe}_{3} \mathrm{O}_{4}$ NPs. Characteristics of NPs and the solvents used in this work are shown in Table 1.

\subsection{Characterization and stability of NPs}

For the fully characterization of NPs, the obtained NPs suspensions were analyzed with dynamic light scattering (DLS) to determine the NPs size distribution (and therefore if agglomeration had occurred) in a Nanoparticle Analysis System (Malvern, UK). DLS is a well-known tool to determine the hydrodynamic diameter of colloidal particles. Zeta Potential (ZP) measurements were also performed for study some surface properties, and changes after the experiments. ZP is a useful technique to study NPs stability and their surface charge in colloids when they are electrostatically stabilized. X-Ray Diffraction spectra (using a PANalytical X’Pert diffractometer using a $\mathrm{Cu} \mathrm{K} \alpha$ radiation source) have also been taken to determine the crystalline phase of the samples. Transmission electron microscope (TEM, using a JEOL 1010 operating at an accelerating voltage of $80 \mathrm{kV}$ ) images of the samples were also taken after NPs

synthesis (Fig. 1), to characterize the NPs, and after the toxicity experiments. In all cases the sizes of NPs responded similarly before and after the experiments, showing no 
relevant differences in shape and size (data not shown).

The details and also the importance of the fully characterization of the NPs, and other factors as stability (agglomeration of NPs changes doses and their physicochemical and morphological properties), concentration at which NPs are obtained and used (that correspond to those currently being developed for applications which, in the near future, we anticipate might exert an environmental impact), the solvent in which nanoparticles are dispersed (presence of salts or other stabilizers, adsorption of molecules from the environment), have been extensively discussed in our previous works [23]. The details of the characterization of NPs used in this work are shown in Table 1.

\subsection{Germination index}

The phytotoxicity of NPs was evaluated by the seed germination technique. The germination index has been extensively used as an indicator of phytotoxicity in soils [24-25]. Several seeds such as Lactuca sativa, Cucumis sativus, Solanum lycopersicum, Spinacia oleracea, Allium porrum and Capsicum annuum were used for this test. After 5 days of incubation of 20 seeds at $25^{\circ} \mathrm{C}$ for each experiment, the seed germination percentage and root length of the seeds were determined. The seed germination percentage and root elongation of seeds in distilled water were also measured and used as a control experiment. Experiments were done in triplicate. The percentages of relative root elongation (E) and germination index (GI) were calculated according to standard methods using Equations 1-3 [24, 25, 26]:

Relative root elongation $=\frac{\text { Mean root length with NPs }}{\text { Mean root length with control }} \times 100$ 
Germination index $=\frac{\text { Relative seed germination }}{\text { Relative root elongation }} \times 100$

where:

Relative seed germination $=\frac{\text { Seeds germinated with NPs }}{\text { Seeds germinated with control }} \times 100$

It is important to note that the germination index combines germination and root growth and consequently it is a more complete toxicity parameter. The root elongation is the percentage of root length compared to control and it can be an indication of the presence of stress effects or other non-acute toxicological effects in the plant evolution. Hence, the root elongation can be more sensitive than germination index when the toxicity affects directly the root development [23].

\subsection{Daphnia magna assays}

Acute $48 \mathrm{~h}$ toxicity assays with D. magna were conducted following Organisation for Economic Co-operation and Development (OECD) protocols with only minor modifications [27]. This kind of tests using little crustaceans like D. magna or even fish (zebrafish, rainbow trout) are commonly used and are internationally accepted for the evaluation of the toxicity of water and wastewater [28]. Groups of 10 neonates $(<24 \mathrm{~h}$ old) were exposed to $20 \mathrm{ml}$ of test concentrations in $50 \mathrm{ml}$ borosilicate flasks with no food present. Each treatment was replicated 3 times. At the end of exposures, immobile animals were recorded and median lethal concentration levels $\left(\mathrm{LC}_{50}\right)$ was calculated using probit procedures [29]. Experiments included several ranges of nanoparticles concentrations and their stabilizers. Firstly assays of high concentration were conducted. Then, the concentration levels were gradually reduced until $\mathrm{LC}_{50}$ was found 
$\mathrm{pH}$ of stabilizers and NPs samples were previously adjusted to 7.0.

\subsection{Microtox bioluminescence test}

A Microtox ${ }^{\circledR}$ system from Microbics Corporation was used. This method is based on the percentage of decrease in the amount of light emitted by the bioluminescent marine bacterium Vibrio fischeri upon contact with a filtered sample at $\mathrm{pH}$ 7. Toxicity is, then, inversely proportional to the intensity of light emitted after the contact with the toxic substances [30]. The effective concentration, $\mathrm{EC}_{50}$, is defined as the concentration that produces a $50 \%$ light reduction. $\mathrm{EC}_{50}$ was measured after 5 and 15 min contact time. Toxicity tests for stabilizer samples and nanoparticles suspensions samples were performed in triplicate, $\mathrm{pH}$ of stabilizers and nanoparticles suspension samples was previously adjusted to 7 . No visible precipitate was observed during the adjustment. Bioluminescent tests were performed under a sodium chloride concentration of $2 \%$ according to the manufacturer's instructions. No visible precipitate was observed during the test, which confirmed nanoparticles stability during the test period.

\subsection{Statistics}

All toxicity tests were performed in triplicate. Statistical significance of values was checked by means of the Levene F-test (variance analysis) and t-Student test (mean analysis) both at 5\% level of probability using the SPSS 15.0 package software (SPSS International, Chicago, IL). Statistically significant values were reported in the results when the probability of the result assuming the null hypothesis (p) is less than 0.05 . 


\section{Results}

\subsection{Germination toxicity}

The main results obtained in the germination test using several seeds are presented in Table 2 expressed as combined germination index (Equation 2). Allium porrum and Capsicum annuum did not show any germination and were discarded. Typically, this test is used for aqueous extracts that may present some phytotoxic compounds, for instance, extracts from unstable compost or other types of organic fertilizers such as pig manure [23-24]. It is also typical to conduct this test on several seeds as it is known that the response can be different for each plant specie, and in some cases some seeds do not show germination depending on the conditions used [31]. In the case of the NPs studied, oxide cerium NPs exhibit a high toxicology for all the seeds tested at the maximum stable concentration $(0.64 \mathrm{mg} / \mathrm{ml})$. When dilutions of this concentration were prepared, the effect was a slightly reduction of toxicity, as shown in Fig. 2. However, a reduction up to $10 \%(0.064 \mathrm{mg} / \mathrm{ml})$ still maintained a level of inhibition of germination around $80 \%$, although the response is significantly different for the different seeds tested.

Contrarily, titanium dioxide NPs exhibited lower toxicity, which in some cases could be attributed to the effect of the stabilizer (Table 2). As it can be seen in Table 2, effect of titanium stabilizers on seeds of Lactuca sativa, Solanum lycopersicum and Spinacia oleracea was greater than the suspension of NPs. This might be explained by adsorption of stabilizer molecules onto the surface of NPs, thus reducing the concentration (dose) of available stabilizer. Although germination tests are not common with NPs, similar results have been obtained with alumina NPs using several seeds [32]. In the case of iron oxide NPs, a average toxicity was observed for both the stabilizer, 
probably because of the low concentration needed (Table 1) and NPs. Our previous results with iron oxide NPs also showed low or no toxicity for these NPs and its stabilizer [23], which was justified by the generally non-toxic character of iron at the low concentrations, which has even been proposed for bioremediation of other pollutants [33].

Nevertheless, it is worthwhile to mention that the differences in the germination test found for each seed were statistically significant in all cases. This implies that a different response is to be expected for any seed, which makes the interpretation of the results relatively difficult. Some authors have demonstrated that little differences in the surface of the NPs can be crucial for their phytotoxic properties [32]. However, it is evident that the standardization of this test is practically impossible given the variety of NPs and seeds.

\subsection{Daphnia magna mortality}

The results obtained with D. magna standard acute toxicology test are presented in Table 3 expressed as $\mathrm{LC}_{50}$. This test is proposed in some regulations and some results have been published for titanium dioxide NPs [34], where one of the main conclusions was that the pretreatment of NPs was essential for its toxicological properties, although it is important to highlight that this work was based on non-solid NPs.

Cerium and titanium dioxide NPs were equally toxic to D. magna having similar values of $\mathrm{LC}_{50}(0.012 \mathrm{mg} / \mathrm{ml}$ and $0.016 \mathrm{mg} / \mathrm{ml}$, respectively). Although no results have been found in literature for cerium oxide NPs, the results for titanium dioxide are within the same order of magnitude than those found by [34]. The previous study reported values of $50 \%$ mortality for $0.0055 \mathrm{mg} / \mathrm{ml}(0.0055 \mathrm{mg} / \mathrm{ml}$ compared to $0.016 \mathrm{mg} / \mathrm{ml}$ 
reported in Table 3) for filtered oxide titanium NPs. Differences in $\mathrm{LC}_{50}$ values between our and Lovern et al [34] study may be attributed to the different way of preparing NPs solutions.

In our study, D. magna showed an extreme sensibility to iron oxide NPs $\left(\mathrm{LC}_{50}=\right.$ $23 \cdot 10^{-4} \mathrm{mg} / \mathrm{ml}$ ). In fact, dead animals showed black aggregates inside their body. Unfortunately, no literature values have been found to compare these results, which would be of special interest since iron oxide nanoparticles are broadly used in several fields and they are generally considered non toxic materials [35-36].

Finally, it should be noticed that stabilizers used do not provoke any significant toxicological effect on D. magna, except in the case of TMAOH, where a weak effect was observed. However, toxicity of samples containing NPs was always significantly higher than the stabilizer alone. This phenomenon is clearly different than the results observed in the germination tests.

\subsection{Bioluminescence toxicity}

Bioluminescence tests such as Microtox ${ }^{\circledR}$ have been routinely applied to treated wastewaters as a standard measure of toxicity and they are included in several international regulations. However, their use with inorganic NPs is very scarce and related to NPs used in aquatic environments [37], although a general lack of data is notorious. In our previous work, no toxicity was detected for $\mathrm{Ag}-\mathrm{NPs}, \mathrm{Au}-\mathrm{NPs}, \mathrm{Fe}_{3} \mathrm{O}_{4-}$ NPs and their respective stabilizers [23]. However, it must be considered that in our first study the methodology used only allows to determine $\mathrm{LC}_{50}$ values lower than $45 \%$ of the initial NPs concentration. In this work, we have used a methodology to determine $\mathrm{LC}_{50}$ values up to $95 \%$ of the initial NPs concentration (Table 1). The results are 
presented in Table 4.

Cerium oxide NPs exhibited again an important toxicity with this test, being the inhibition produced higher than $80 \%$ at $10 \%$ of the maximum concentration $(0.64$ $\mathrm{mg} / \mathrm{ml})$. This again highlights the high toxicity of this type of NPs. To our knowledge, only one work has been published on oxide cerium NPs toxicity in aquatic environments, particularly in crustaceans [38] and the results were similar to our study. This is of special importance since oxide cerium NPs are increasingly being used as a catalyst in the automotive industry [39] and in other medical applications [39].

In the case of the other two NPs studied, titanium dioxide NPs showed practically no toxicity, and only an inhibition of $21 \%$ of the light emitted was detected at the maximum concentration, being practically negligible when NPs were slightly diluted. On the contrary, iron oxide NPs showed a clear sigmoid trend of toxicity when increasing the NPs concentration (Fig. 3), resulting in an $\mathrm{EC}_{50}$ value of $0.24 \mathrm{mg} / \mathrm{ml}$. It is also worthwhile to mention that no differences were observed between the exposure to NPs of Vibrio fischeri during 5 and 15 minutes, a procedure that is recommended in Microtox ${ }^{\circledR}$ commercial test to distinguish between the types of toxicological effects that the substance can provoke on the bacterium. As it can be seen from Fig. 3 inhibition evolution at 5 and 15 minutes was very similar. This could indicate that toxicity effects of iron NPs are produced at very short term exposition. These values are also of interest since our previous study only showed a moderate toxicity when iron oxide NPs were exposed the $45 \%$ of the maximum stable concentration $(0.052 \mathrm{mg} / \mathrm{ml})$ [23]. Finally, none of the stabilizers showed detectable toxicity using this test.

\section{Discussion}


Although there is no an international consensus about what toxicity tests should be used for NPs, it is important to note that the results provided in this study can help in deciding which is/are the most suitable test/s. In fact, in some cases, a base set of tests is recommended to determine the toxicity of a given NPs to extract reliable conclusions about its toxicological effects [40].

From the results obtained, it is clear that the germination tests do not seem to be adequate for determining NPs toxicity. Although in some particular cases the germination tests can be of interest [41-42], the results obtained for germination in this work and in our previous work with $\mathrm{Ag}-\mathrm{NPs}, \mathrm{Au}-\mathrm{NPs}$ and $\mathrm{Fe}_{3} \mathrm{O}_{4}-\mathrm{NPs}$ [23] are hardly reproducible. Firstly, it is not clear why some seeds do not germinate under any conditions (Allium porrum and Capsicum annuum) while in other studies are successfully used to determine compost extract toxicity [31]. In second place, it is not evident why the stabilizers of NPs have an important effect in the germination, whereas in the other tests (D. magna and bioluminescence), the toxicity is practically negligible. Moreover, some of the toxicological results obtained with this test (Table 2) do not present a proportional toxicological response to the concentration of stabilizer, which should be expected.

On the contrary, D. magna and Microtox tests provide what seems more reliable and reproducible information about NPs toxicity. Particularly, D. magna test gives accurate information about the levels of mortality (or survival) of animals directly exposed to the pollutant and permits an easy calculation of $\mathrm{LC}_{50}$ (Table 3). This has been also observed by other authors with titanium dioxide NPs and fullerene, where their toxicity was studied in detail with D. magna after different treatments [34]. None of the stabilizers used in NPs tests show any toxicity.

Finally, to our knowledge, Microtox has not been extensively applied to evaluate 
the toxicity of NPs solutions. As commented previously, in our previous work [23], no toxicity was detected for $\mathrm{Ag}-\mathrm{NPs}, \mathrm{Au}-\mathrm{NPs}, \mathrm{Fe}_{3} \mathrm{O}_{4}-\mathrm{NPs}$ and their respective stabilizers. However, the method used in that work only permitted to detect toxicity when the NPs concentration was $45 \%$ of the maximum stable concentration. In the present study no limitation of NPs concentration existed and this test allowing to detect toxic effects of iron oxide, cerium oxide and titanium dioxide NPs (Table 4). Moreover, no toxicity was found for stabilizers (in the maxim concentration) using this bioluminescence test. In consequence, and although this test obviously needs specific equipment (luminometer), its implementation, start-up and operation procedures make it very simple to be proposed for future studies with other NPs.

\section{Conclusions}

The standardized tests proposed in this study have proved to be very useful in the determination of NPs toxicity when no or few data are available. Among the different tests proposed, luminescence and Microtox tests have demonstrated to be very useful in the determination of $\mathrm{LC}_{50}$ values to be compared with other works published in literature, whereas more work is necessary to obtain reliable conclusions about the use of germination tests.

\section{Acknowledgements}

Financial support was provided by the Spanish Ministerio de Medio Ambiente y Medio Rural y Marino (Project Exp. 007/RN08/03.1). 


\section{References}

[1]Varanasi, P., A. Fullana, S. Sidhu. Remediation of PCB contaminated soils using iron nano-particles. Chemosphere 66 (2007) 1031-1038.

[2]Limbach, L.K., R. Bereiter, E. Muller, R. Krebs, R. Galli, W.J. Stark. Removal of Oxide nanoparticles in a Model Wastewater Treatment Plant: Influence of Agglomeration and Surfactants on Clearing Efficiency. Environ. Sci. Technol. 42 (2008) 5828-5833.

[3]Karn, B., T. Kuiken, M. Otto. Nanotechnology and In situ Remediation: A review of the benefits and potential risks. Environ. Health Persp. Available on-line: doi: 10.1289/ehp.0900793

[4]Choi, J.Y., S.H. Lee, H.B. Na, K. An, T. Hyeon, T.S. Seo. In vitro cytotoxicity screening of water-dispersible metal oxide nanoparticles in human cell lines. Bioprocess. Biosyst. Eng. Available on-line: doi: 10.1007/s00449-009-0354-5.

[5]Brunner, T.J., P. Wick, P. Manser, P. Spohn, R.N. Grass, L.K. Limbach, A. Bruinink, W.J. Stark. In vitro cytotoxicity of oxide nanoparticles: comparison to Asbestos, Silica and the effect of particle solubility. Environ. Sci. Technol. 40 (2006) 4374-4381.

[6]Hu, X., S. Cook, P. Wang, H. Hwang. In vitro evaluation of cytotoxicity of engineered metal oxide nanoparticles. Sci. Total Environ. 407 (2009) 30703072.

[7]Nowack, B., T.D. Bucheli. Occurrence, behavior and effects of nanoparticles in the environment. Environ. Pollut. 150 (2007) 5-22.

[8]Wiesner, M.R., G.V. Lowry, P. Alvarez, D. Dionysiou, P. Biswas. Assessing the risks of manufactured nanomaterials. Environ. Sci. Technol. 40 (2006) 43364345. 
[9]Karakoti, A.S., N.A. Monteiro-Riviere, R. Aggarwal, J.P. Davis, R.J. Narayan, W.T. Self, J. McGinnis, S. Seal. Nanoceria as Antioxidant: Synthesis and Biomedical Applications. Journal of the Minerals, Metals and Materials Society. 60 (2008) $33-37$.

[10]Patil,S., S.Reshetnikov, M.K. Haldar, S. Seal, S. Mallik. Surface-Derivatized Nanoceria with Human Carbonic Anhydrase II Inhibitors and Fluorophores: A Potential Drug Delivery Device. J. Phys. Chem. C. 111 (2007) 8437-8442.

[11]Chen, J., S. Patil, S. Seal, J.F. McGinnis. Rare earth nanoparticles prevent retinal degeneration induced by intracellular peroxides. Nat. Nanotech. 1 (2006) 142150.

[12]Park, B., P. Martin, C. Harris, R. Guest, A. Whittingham, P. Jenkinson, J. Handley. Initial in vitro screening approach to investigate the potential health and environmental hazards of EnviroxTM - a nanoparticlulate cerium oxide diesel fuel additive. Particle and Fibre Toxicology, 4:12 (2007).

[13]Pankhurst, Q.A., J. Connolly, S.K. Jones, J. Dobson. Applications of magnetic nanoparticles in biomedicine. J. Phys. D: Appl. Phys. 36 (2003) R167-R181.

[14]Huber, D.L. Synthesis, Properties, and Applications of Iron Nanoparticles. Small. 1 (2005) 482-501.

[15]Wang, J., L. Jin, L. Xue, Y. Qu, H. Fu. Enhanced activity of bismuth-compounded $\mathrm{TiO}_{2}$ nanoparticles for photocatalytically degrading rhodamine B solution. J. Hazar. Mat. 160 (2008) 208-212.

[16]Dunford, R., A. Salinaro, L.Z. Cai, N. Serpone, S. Horikoshi, H. Hidaka, J. Knowland. Chemical oxidation and DNA damage catalysed by inorganic sunscreen ingredients. FEBS Lett. 418 (1997) 87-90.

[17]Hidaka, H., S. Horikoshi, N. Serpone, J. Knowland. In vitro photochemical damage 
to DNA, RNA and their bases by an inorganic sunscreen agent on exposure to UVA and UVB radiation. J. Photochem. Photobiol. A-Chem. 111 (1997) 205213.

[18]Guix, M., C. Carbonell, J. Comenge, L. García-Fernández, A. Alarcón, E. Casals, V. Puntes. Nanoparticles for cosmetics. How safe is safe? Contribution to Science. 4(2) (2008).

[19]Zhang, F., Q. Jin, S.W. Chan. Ceria nanoparticles: Size, size distribution, and shape. J. Appl. Phys. 95 (2004) 4319-4326.

[20]Pottier, A., S. Cassaignon, C. Chaneac, F. Villain, E. Tronca, J-P. Jolivet. Size tailoring of $\mathrm{TiO}_{2}$ anatase nanoparticles in aqueous medium and synthesis of nanocomposites. Characterization by Raman spectroscopy. J. Mater. Chem. 13 (2003) 877-882.

[21]Massart, R. Preparation of Aqueous Magnetic Liquids in Alkaline and Acidic Media. IEEE Trans. Magn. 17 (1981) 1247.

[22]Jolivet, J.P., R. Massart, J.M. Fruchart. Synthesis and physicochemical study on nonsurfactant magnetic colloids in aqueous medium. New J. Chem. 7 (1983) $325-331$

[23]Barrena, R., E. Casals, J. Colón, X. Font, A. Sánchez, V. Puntes. Evaluation of the ecotoxicity of model nanoparticles. Chemosphere 75 (2009) 850-857.

[24]Tiquia, M.S., N.F.Y. Tam. Elimination of phytotoxicity during co-composting of spent pig-manure sawdust litter and pig sludge. Bioresource Technol. 65 (1998) 43-49.

[25]The U.S. Department of Agriculture and The U.S. Composting Council, 2001. Test methods for the examination of composting and compost. Edaphos International, Houston. 
[26]Tiquia, M.S., N.F.Y. Tam, I.J. Hodgkiss. Effects of composting on phytotoxicity of spent pig-manure sawdust litter. Environ. Pollut. 93 (1996) 249-256.

[27]Barata, C., D.J. Baird. Determining the ecotoxicological mode of action of chemicals from measurements made on individuals: results from short-duration chronic tests with Daphnia magna Straus. Aquatic Toxicol. 48 (2000) 195-209.

[28]Sharma, V.K. Aggregation and toxicity of titanium dioxide nanoparticles in aquatic environment-A Review. J. Environ. Sci. Health Part A-Toxic/Hazard. Subst. Environ. Eng. 44 (2009) 1485-1495.

[29]Finney, D.J., 1971. Probit Analysis, third ed. Cambridge University Press, Cambridge, UK.

[30]DIN 38412, Part 34, 1991. Determination of the inhibitory effect of wastewater on the light emission of Photobacterium phosphoreum (test using preserved luminescent bacteria).

[31]Komilis, D.P., I.S. Tziouvaras. A statistical analysis to assess the maturity and stability of six composts. Waste Manage. 29 (2009) 1504-1513.

[32]Yang, L., D.J. Watts. Particle surface characteristics may play an important role in phytotoxicity of alumina nanoparticles. Toxicol. Lett. 158 (2005) 122-132.

[33]Yavuz, C.T., J.T. Mayo, W.W. Yu, A. Prakash, J.C. Falkner, S. Yean, L.L. Cong, H.J. Shipley, A. Kan, M. Tomson, D. Natelson, V.L. Colvin. Low-Field Magnetic Separation of Monodisperse $\mathrm{Fe}_{3} \mathrm{O}_{4}$ Nanocrystals. Science. 314 (2006) 964-967.

[34]Lovern, S.B., R. Klaper. Daphnia magna mortality when exposed to titanium dioxide and fullerene $\left(\mathrm{C}_{60}\right)$ nanoparticles. Environ. Toxicol. Chem. 25 (2006), 1132-1137.

[35]Ju-Nam, Y., J.R. Lead. Manufactured nanoparticles: An overview of their 
chemistry, interactions and potential environmental implications. Sci. Total Environ. 400 (2008) 396-414.

[36]Bystrzejewska-Piotrowska, G., J. Golimowski, J.P. Urban. Nanoparticles: Their potential toxicity, waste and environmental management. Waste Manage. 29 (2009) 2587-2595.

[37]Farré, M., S. Pérez, L. Kantiani, D. Barceló. Fate and toxicity of emerging pollutants, their metabolites and transformation products in the aquatic environment. Trends Anal. Chem. 27 (2008) 991-1007.

[38]Van Hoecke, K., J.T.K. Quik, J. Mankiewicz-Boczek, K.A.C. De Schamphelaere, A. Elsaesser, P. Van der Meeren, C. Barnes, G. McKerr, C.V. Howard, D. Van De Meent, K. Rydzyski, K.A. Dawson, A. Salvati, A. Lesniak A.I. Lynch, G. Silversmit, B. De Samber, L. Vincze, C.R. Janssen. Fate and Effects of $\mathrm{CeO}_{2}$ Nanoparticles in Aquatic Ecotoxicity Tests. Environ. Sci. Technol. 43 (2009), $4537-4546$.

[39]Scirè, S., S. Minicò, C. Crisafulli, C. Satriano, A. Pistone. Catalytic combustion of volatile organic compounds on gold/cerium oxide catalysts Appl. Cat. B: Environ. 40 (2003) 43-49.

[40]Azarmi, S., W.H. Roa, R. Löbenberg. Targeted delivery of nanoparticles for the treatment of lung diseases Adv. Drug Delivery Rev. 60 (2008) 863-875.

[41]Warheit, D.B., R.A. Hoke, C. Finlay, E.M. Donner, K.L. Reed, C.M. Sayes. Development of a base set of tests using ultrafine $\mathrm{TiO}_{2}$ particles as a component of nanoparticles risk management. Toxicol. Lett. 171 (2007) 99-110.

[42]Lin, D., B. Xing. Phytotoxicity of nanoparticles: inhibition of seed germination and root growth. Environ. Pollut. 150 (2007) 243-250. 


\section{Tables}

Table 1:Main characteristics of the nanoparticles used.

\begin{tabular}{lccc}
\hline Nanoparticle & $\mathrm{CeO}_{2}$ & $\mathrm{TiO}_{2}$ & $\mathrm{Fe}_{3} \mathrm{O}_{4}$ \\
\hline Concentration $(\mathrm{mg} / \mathrm{ml})$ & 0.64 & 1.12 & 0.67 \\
Mean size (nm) & 6.5 & 7.5 & 6.0 \\
Shape & shapeless & shapeless & spherical \\
Zeta potential (mV) & +11.5 & -42.5 & -58.4 \\
Stabilizer* & $\mathrm{HMT}$ & $\mathrm{TMAOH}$ & $\mathrm{TMAOH}$ \\
Stabilizer concentration $(\mathrm{mM})$ & 8.3 & 10 & 1 \\
pH (original) & 9 & 10 & 10 \\
\hline
\end{tabular}

*HMT: Hexamethylenetetramine; TMAOH: Tetramethylammonium Hydroxide. 
Table 2: Toxicity results expressed as germination index (\%) obtained with the germination test. Allium porrum and Capsicum annuum did not show positive response to germination test and were discarded.

\begin{tabular}{|c|c|c|c|c|c|c|}
\hline Seed & $\begin{array}{c}\mathrm{CeO}_{2} \\
(0.64 \mathrm{mg} / \mathrm{ml})\end{array}$ & $\begin{array}{c}\text { HMT* }^{*} \\
(8.3 \mathrm{mM})\end{array}$ & $\begin{array}{c}\mathrm{TiO}_{2} \\
(1.12 \mathrm{mg} / \mathrm{ml})\end{array}$ & $\begin{array}{l}\text { TMAOH* }^{*} \\
(10 \mathrm{mM})\end{array}$ & $\begin{array}{c}\mathrm{Fe}_{3} \mathrm{O}_{4} \\
(0.67 \mathrm{mg} / \mathrm{ml})\end{array}$ & $\begin{array}{c}\mathrm{TMAOH}^{*} \\
(1 \mathrm{mM})\end{array}$ \\
\hline $\begin{array}{l}\text { Lactuca } \\
\text { sativa }\end{array}$ & 0 & 61 & 60 & 15 & 36 & 25 \\
\hline $\begin{array}{l}\text { Cucumis } \\
\text { sativus }\end{array}$ & 0 & 24 & 40 & 72 & 26 & 36 \\
\hline $\begin{array}{l}\text { Solanum } \\
\text { lycopersicum }\end{array}$ & 0 & 5 & 54 & 47 & 13 & 12 \\
\hline $\begin{array}{l}\text { Spinacia } \\
\text { oleracea }\end{array}$ & 0 & 0 & 45 & 25 & 0 & 4 \\
\hline
\end{tabular}

*HMT: Hexamethylenetetramine; TMAOH: Tetramethylammonium Hydroxide. 
Table 3: Mortality in the assays of Daphnia magna. $\mathrm{LC}_{50}$ and its corresponding limits are expressed in $\mathrm{mg} / \mathrm{ml}$.

\begin{tabular}{cccc}
\hline Sample & $\mathrm{LC}_{50}$ & Upper limit & Lower limit \\
\hline $\mathrm{CeO}_{2}$ nanoparticles & 0.012 & 0.011 & 0.015 \\
$\mathrm{TiO}_{2}$ nanoparticles & 0.016 & 0.013 & 0.020 \\
$\mathrm{Fe}_{3} \mathrm{O}_{4}$ nanoparticles & $2.3 \cdot 10^{-4}$ & $1.7 \cdot 10^{-4}$ & $3.8 \cdot 10^{-4}$ \\
$\mathrm{HMT}^{*}(8.33 \mathrm{mM})$ & No toxic & - & - \\
$\mathrm{TMAOH}^{*}(\mathrm{mM})$ & 0.041 & 0.021 & 0.067 \\
\hline
\end{tabular}

*HMT: Hexamethylenetetramine; TMAOH: Tetramethylammonium Hydroxide. 
Table 4: Toxicity results obtained with the bioluminescence test.

\begin{tabular}{cc}
\hline Sample & Toxicity \\
\hline $\mathrm{CeO}_{2}$ nanoparticles & Inhibition was higher than $80 \%$ at the minimum \\
concentration tested $(0.064 \mathrm{mg} / \mathrm{ml})$ \\
$\mathrm{TiO}_{2}$ nanoparticles & Only $21 \%$ of inhibition was detected at the \\
$\mathrm{Fe}_{3} \mathrm{O}_{4}$ nanoparticles & maximum concentration tested $(1.12 \mathrm{mg} / \mathrm{ml})$ \\
$\mathrm{HMT}^{*}(\mathrm{mM})$ & EC $_{50}$ was $0.24 \mathrm{mg} / \mathrm{ml}$ \\
$\mathrm{TMAOH}^{*}(\mathrm{mM})$ & No toxicity detected $(8.33 \mathrm{mM})$ \\
\end{tabular}

*HMT: Hexamethylenetetramine; TMAOH: Tetramethylammonium Hydroxide. 


\section{Figure Legends}

Figure 1: TEM images of the samples after nanoparticles synthesis. a) cerium oxide nanoparticles; b) titanium oxide nanoparticles; c) iron oxide nanoparticles (Scale: 200 $\mathrm{nm})$.

Figure 2: Percentage of inhibition obtained with different dilutions of $\mathrm{CeO}_{2}$ nanoparticles using selected seeds.

Figure 3: Determination of $\mathrm{EC}_{50}$ using $\mathrm{Fe}_{3} \mathrm{O}_{4}$ nanoparticles using the bioluminescence toxicity test. Concentrations of percentage of inhibition (x-axis) correspond to 0.64$0.32-0.128-0.064 \mathrm{mg} / \mathrm{ml}$. 
Figure 1: García et al.

a)

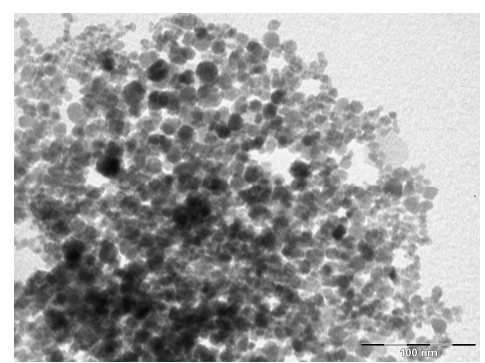

b)

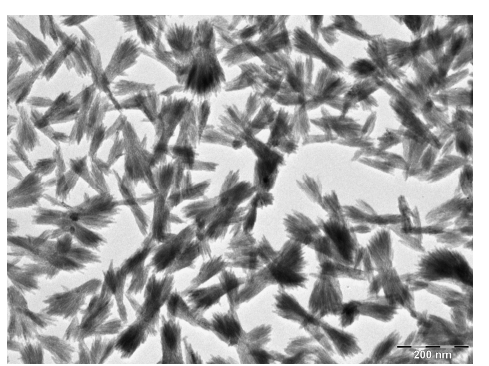

c)

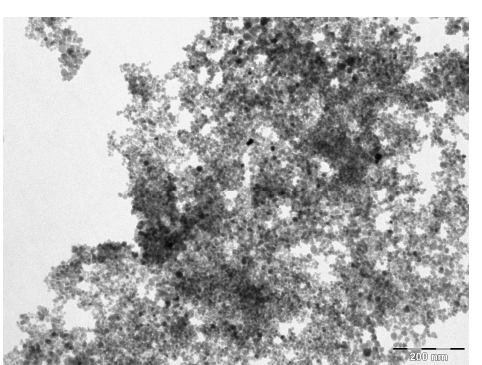


Figure 2: García et al.

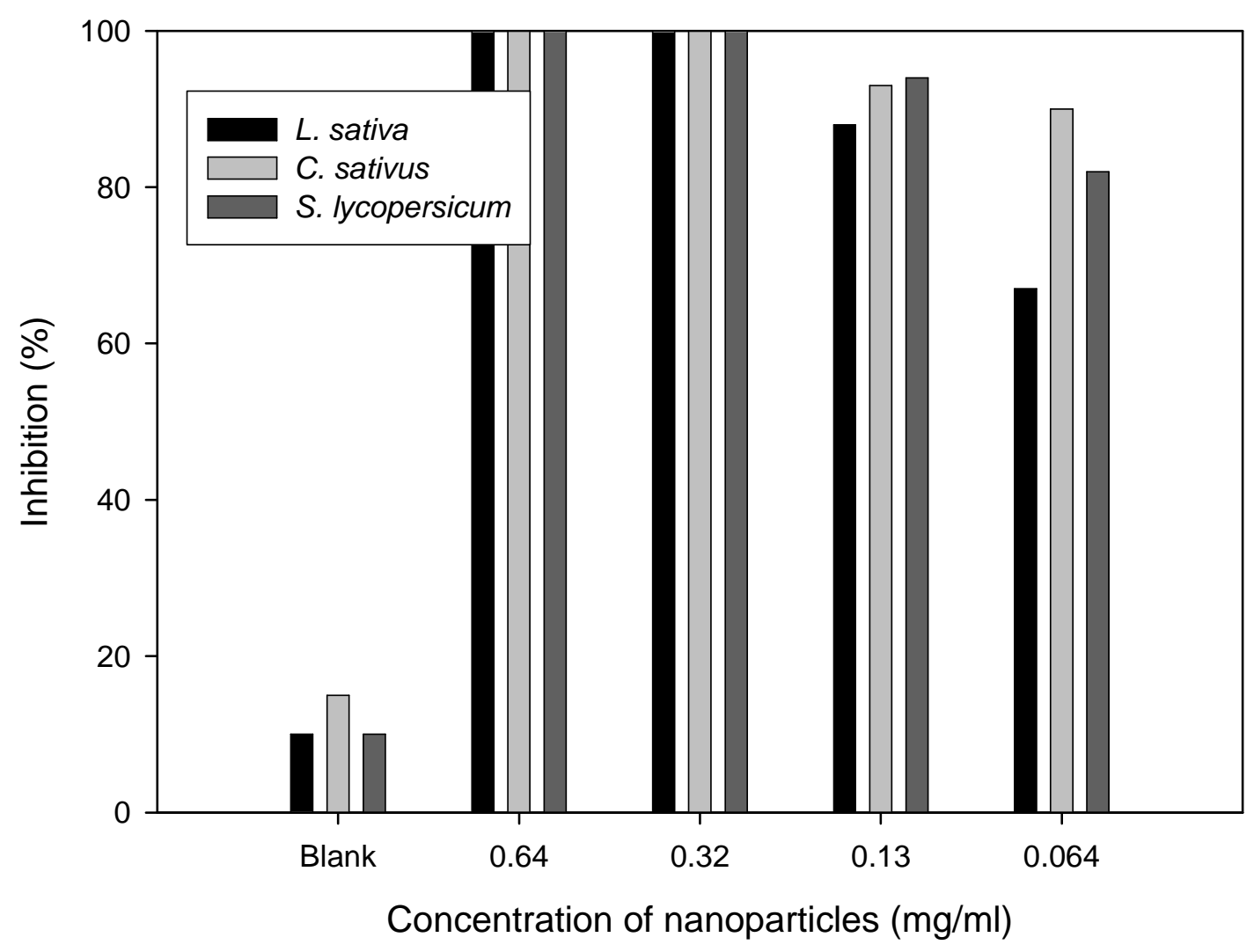


Figure 3: García et al.

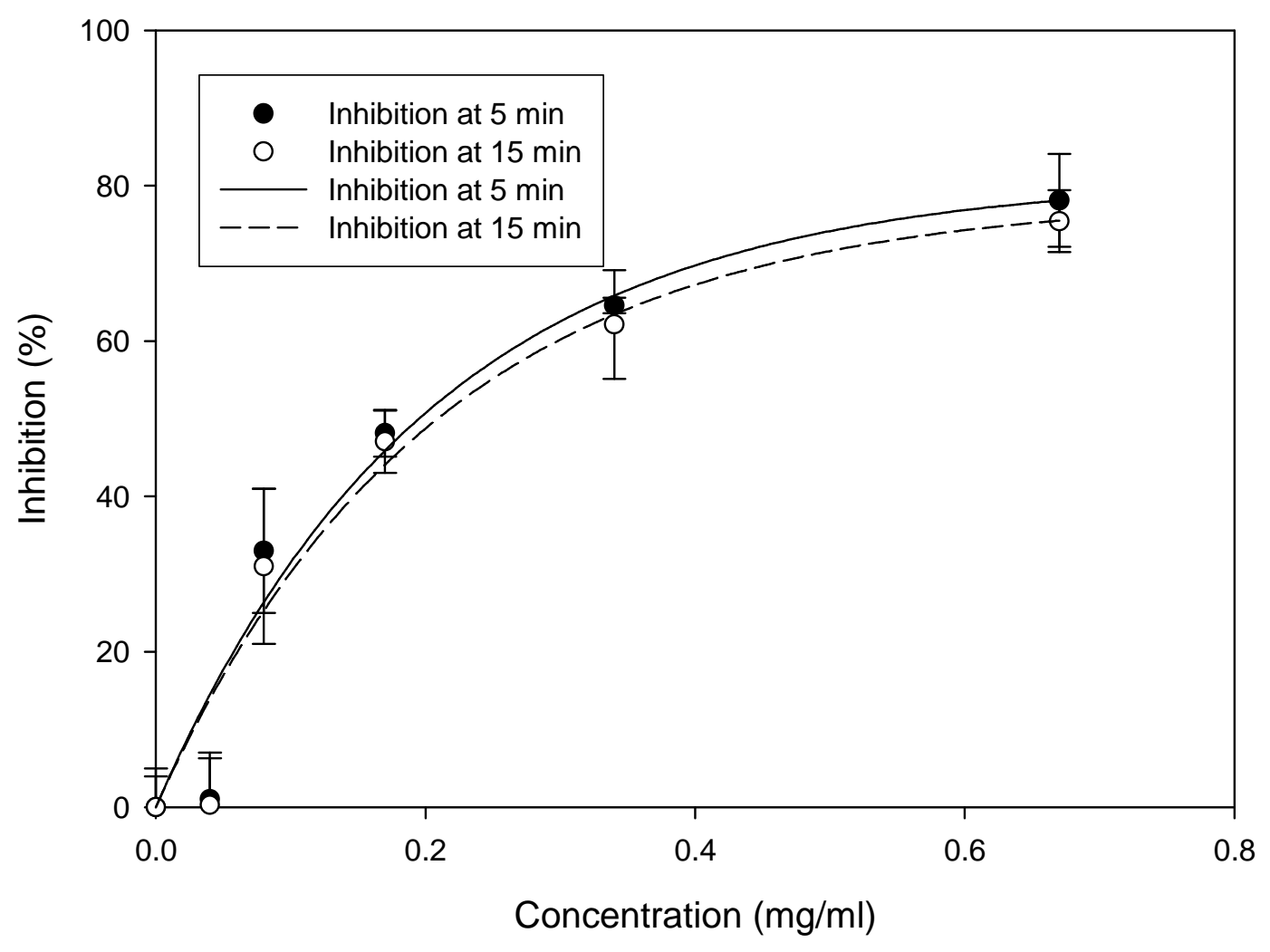

